\title{
Photoelectrochemical and Photo-Fenton Mechanism of Enhanced Visible Light-Driven Nanocatalyst Synthesis of ZnFe204/BiOl
}

chao li

Lanzhou University of Technology

Zhiqiang Wei ( $\nabla$ qianweizuo@163.com )

Lanzhou University of Technology https://orcid.org/0000-0002-1173-9412

Qiang Lu

Lanzhou University of Technology

Huan Jin Ma

Lanzhou University of Technology

Ling Li

Lanzhou University of Technology

\section{Research Article}

Keywords: ZnFe204, BiOI, Nanocomposites, Photoelectrochemical property, Photo-Fenton, Z-Scheme heterojunction

Posted Date: December 6th, 2021

DOI: https://doi.org/10.21203/rs.3.rs-1004080/v1

License: (c) (i) This work is licensed under a Creative Commons Attribution 4.0 International License. Read Full License

Version of Record: A version of this preprint was published at Environmental Science and Pollution Research on January 18th, 2022. See the published version at https://doi.org/10.1007/s11356-02218682-5. 


\section{Abstract}

Based on the fact that the photo-Fenton process can directly use solar energy to degrade various pollutants, it has received widespread attention. However, it has attracted widespread attention due to the rapid recombination of photo-generated carriers and the low light response range. Therefore, the construction of a Z-scheme heterojunction in this paper can effectively enhance the electron-hole separation, increase the reduction and oxidation potential, and enhance the redox capability of the photocatalyst. This paper reports the successful preparation of visible-light-induced $\mathrm{ZnFe}_{2} \mathrm{O}_{4} / \mathrm{BiOI}$ composite photocatalyst. There is a Z-scheme heterojunction structure of $\mathrm{ZnFe}_{2} \mathrm{O}_{4}$ and $\mathrm{BiOI}$. At the same time, the PL and UV absorption spectra showed that the light absorption performance of the composite nanomaterials was enhanced, the photo-generated carriers recombination rate was reduced, and the photo-Fenton performance was also significantly improved. And the photocurrent of $\mathrm{ZnFe}_{2} \mathrm{O}_{4} / \mathrm{BiOl}$ is more than 29 times that of pure $\mathrm{ZnFe}_{2} \mathrm{O}_{4}$. In addition, $\mathrm{ZnFe}_{2} \mathrm{O}_{4} / \mathrm{BiOl}$ can degrade the simulated pollutant $\mathrm{RhB} 100 \%$ within 20 min under simulated sunlight. It shows that $\mathrm{ZnFe}_{2} \mathrm{O}_{4} / \mathrm{BiOl}$ binary composite has excellent photo-Fenton properties. In addition, $\mathrm{ZnFe}_{2} \mathrm{O}_{4} / \mathrm{BiOl}$ still maintains a high photo-Fenton ability after three cycles. Therefore, it has potential application prospects of the industrial photodegradation of organic pollutants.

\section{Introduction}

In recent decades, with the rapid development of global industrialization and the large-scale application of organic dyes, the shortage of freshwater resources and water pollution have become a global problem facing human society. It has attracted significant attention to scholars at home and abroad.(Chen et al. 2018, Hasija et al. 2019, Hu et al. 2019, Sharma \&Feng 2019, Yang et al. 2020) Traditional semiconductor photocatalysts (such as $\mathrm{TiO}_{2}$ and $\mathrm{ZnO}$ ) can only respond to ultraviolet light and have low utilization in the visible light band; photo-generated electron-hole pairs are elementary to recombine, and the photocatalytic efficiency is low; powdered catalysis are challenging to separate from the reaction solution, it will cause the loss of motivation and secondary pollution of the water. (Guo et al. 2019a, Guo et al. 2019b, Meng et al. 2019, Wu et al. 2020, Yendrapati et al. 2020, Zhou et al. 2020b) Therefore, it is urgent to develop more superior water treatment technologies to solve these problems and realize the sustainable development of human society. The researchers have combined the advantages of ironbased oxide photocatalysis technology and Fenton oxidation technology to realize the cycle of the photoFenton process, which makes the system produce more $\cdot \mathrm{OH}$ with solid oxidizing ability, thereby enhancing the degradation of pollutants in wastewater effectiveness.(Clarizia et al. 2017, Mirzaei et al. 2017, Xing et al. 2018) Photo-Fenton technology has unique advantages such as low preparation cost, fast degradation rate and less secondary pollution. It has shown broad application prospects of the use of solar energy to degrade pollutants.(Huang et al. 2017, Liu et al. 2017, Zhang et al. 2019)

The spinel structures metal oxide belongs to the cubic crystal system, and its general formula is $A_{2} \mathrm{O}_{4}$. The A position represents the tetrahedral position occupied by the divalent metal ion. The tetrahedral gap 
is surrounded by four oxygen ions; the B position means the octahedral position occupied by the trivalent metal ion octahedral void is surrounded by six oxygen ions.(Behera et al. 2019, Jiang et al. 2018, Zhou et al. 2020a) Spinel structure $\mathrm{ZnFe}_{2} \mathrm{O}_{4}$ has the characteristics of non-toxic, stable chemical properties, photochemical corrosion resistance, simple preparation and low cost.(Cai et al. 2016, Chen et al. 2021, Xiang et al. 2020) Compared with traditional photocatalysts, $\mathrm{ZnFe}_{2} \mathrm{O}_{4}$ has a narrower bandgap, is more sensitive to visible light, has a broader spectral response range, and has good photocatalytic activity. (Chen et al. 2010, Zheng et al. 2020)

This paper reports the preparation of spinel structure $\mathrm{ZnFe}_{2} \mathrm{O}_{4}$ by hydrothermal method and the construction of $\mathrm{ZnFe}_{2} \mathrm{O}_{4} / \mathrm{BiOI} \mathrm{Z}$-scheme hetero-junction degradation dyed RhB. Compared with $\mathrm{ZnFe}_{2} \mathrm{O}_{4}$, the photo-Fenton degradation reaction rate of $\mathrm{ZnFe}_{2} \mathrm{O}_{4} / \mathrm{BiOl}$ is 27 times higher than that of $\mathrm{ZnFe}_{2} \mathrm{O}_{4}$, and the reaction rate of $\mathrm{ZnFe}_{2} \mathrm{O}_{4} / \mathrm{BiOl}$ photo-Fenton degradation $\mathrm{RhB}$ is 19 times higher than that of $\mathrm{ZnFe}_{2} \mathrm{O}_{4} / \mathrm{BiOl}$ photocatalytic degradation rate. The origin of photo-Fenton activity improvement is explored to study of structure, morphology, optics and electrochemistry. The main reaction species in the visual Fenton process is the use of various chemical scavengers for research. After three cycles of reaction, the degradation rate of $\mathrm{RhB}$ remained at $81.6 \%$.

\section{Experimental Procedures}

\subsection{Synthesis of $\mathrm{ZnFe}_{2} \mathrm{O}_{4} / \mathrm{BiO}$ heterojunction}

Weigh $0.05 \mathrm{~mol}$ of $\mathrm{Zn}\left(\mathrm{NO}_{3}\right)_{2} \cdot 6 \mathrm{H}_{2} \mathrm{O}$ and $0.1 \mathrm{~mol}$ of $\mathrm{Fe}\left(\mathrm{NO}_{3}\right)_{3} \cdot 6 \mathrm{H}_{2} \mathrm{O}$, respectively, and dissolve them in $40 \mathrm{~mL}$ of deionized water, sonicate for $15 \mathrm{~min}$ and stir for $30 \mathrm{~min}$. Next, adjust the pH to 13 and pass the $6 \mathrm{M} \mathrm{NaOH}$ solution, transfer the mixture to a $100 \mathrm{~mL}$ stainless steel autoclave lined with PTFE, and react at $180^{\circ} \mathrm{C}$ for $24 \mathrm{~h}$. After the samples were cooled to room temperature, they were washed alternately with deionized water and ethanol three times and then placed in an oven at $60^{\circ} \mathrm{C}$ for $8 \mathrm{~h}$. Then the mixture is annealed at $500{ }^{\circ} \mathrm{C}$ for $5 \mathrm{~h}$ to obtain zinc ferrite powder, represented by $\mathrm{ZnFe}_{2} \mathrm{O}_{4}$ (abbreviated as ZFO). Weigh $0.05 \mathrm{~mol} \mathrm{ZnFe}_{2} \mathrm{O}_{4}$ and $0.1 \mathrm{~mol} \mathrm{Bi}\left(\mathrm{NO}_{3}\right)_{3} \cdot 5 \mathrm{H}_{2} \mathrm{O}$ respectively and dissolve them in absolute ethanol. Next, dissolve $0.05 \mathrm{~mol} \mathrm{KI}$ in deionized water and stir until the drug is completely dissolved; Add the KI solution dropwise to $\mathrm{Bi}\left(\mathrm{NO}_{3}\right)_{3} \cdot 5 \mathrm{H}_{2} \mathrm{O}$. Adjust the solution to $\mathrm{pH}=7$, stir for $30 \mathrm{~min}$, transfer to a $100 \mathrm{~mL}$ stainless steel autoclave lined with PTFE, and keep at $100^{\circ} \mathrm{C}$ for $12 \mathrm{~h}$. After the sample is cooled to room temperature, wash with deionized water and ethanol alternately three times. Put it in an oven at $60^{\circ} \mathrm{C}$ and dry it for $8 \mathrm{~h}$ to obtain the composite powder $\mathrm{ZnFe}_{2} \mathrm{O}_{4} / \mathrm{BiOI}$. By changing the molar ratio of $\mathrm{ZnFe}_{2} \mathrm{O}_{4}$ and $\mathrm{BiOI}$ to 1:1, 1:2 and 1:3, a composite photocatalyst was prepared and named ZFO / BOI -1, ZFO / BOI -2 , ZFO / BOI -3. For comparison, pure BiOI (abbreviated as BOI) has also synthesized via the same method without the addition of $\mathrm{ZnFe}_{2} \mathrm{O}_{4}$.

\subsection{Characterization}


X-ray diffractometer (Rigaku, Japan, D/Max-2400 type, Cu Ka radiation, $\lambda=1.54056 \AA$, scanning range of $10-90^{\circ}$, step length of $0.02^{\circ}$ ) was used to analyze the phase structure of the samples. The microscopic morphology and particle size of the materials were observed by scanning electron microscope (SEM, JSM-6701F) and high-resolution transmission electron microscope (HRTEM, JEM-1200EX). The UV-Vis diffuse reflectance spectra (UV-Vis DRS, PERSEE TU-1901) of photocatalysts were recorded by a doublebeam UV-Vis spectrophotometer, using $\mathrm{BaSO}_{4}$ as the reference material (scan interval: $200-850 \mathrm{~nm}$, step size: $0.5 \mathrm{~nm}$ ). The multifunctional X-ray photoelectron spectrometer (XPS, AXIS SUPRA) was used to analyze the chemical element valence state of the materials. Analyze the surface area and pore size distribution of samples using the Specific Surface and Porosity Analyzer (ASAP Model 2020). The photoluminescence $(\mathrm{PL})$ spectrum of the photocatalyst was recorded by a fluorescence phosphorescence luminescence spectrophotometer (LS-55) with an excitation wavelength of $325 \mathrm{~nm}$. The Fourier transform infrared spectra (FT-IR) of the samples were tested by an infrared spectrometer (Spectrum Two) in the range of $500 \sim 4000 \mathrm{~cm}^{-1}$ using $\mathrm{KBr}$ as the background.

\subsection{Photo-electrochemical measurement}

Electrochemical impedance spectra (EIS), transient photocurrent response and Mott-Schottky (M-S) curves of $\mathrm{ZnFe}_{2} \mathrm{O}_{4} / \mathrm{BiOl}$ composite photocatalysts were measured in $\mathrm{Na}_{2} \mathrm{SO}_{4}(0.1 \mathrm{M})$ solution by an electrochemical workstation (CorrTest, CS350) with a typical three-electrode electrolytic cell. A saturated calomel electrode (SCE) was used for the reference electrode. $8 \mathrm{mg}$ photocatalyst and $1 \mathrm{mg}$ acetylene black were ground and mixed evenly, 1-methyl-2-pyrrolidone (NMP) was used as dispersant and polyvinylidene fluoride (PVDF) was used as binder, which were dropped and stirred in turn, and then coated on the surface of conductive glass. After drying at $60{ }^{\circ} \mathrm{C}$, the working electrode was obtained. The electrochemical impedance spectra were measured at a sinusoidal voltage signal of $5 \mathrm{mV}$ in the frequency range of $10^{-2}$ to $10^{5} \mathrm{~Hz}$. The transient photocurrents (l-t curves) were measured at $\square x e d$ bias potential of $0.2 \mathrm{~V}$. The Mott-Schottky (M-S) curves were measured at 3000 and $5000 \mathrm{~Hz}$ in $0.1 \mathrm{M} \mathrm{Na}_{2} \mathrm{SO}_{4}$.

\section{4. photo-Fenton experiment}

Rhodamine B was degraded under simulated sunlight under xenon lamp irradiation to test the photoFenton performance. The initial concentration was $5 \mathrm{mg} / \mathrm{L}$, and the photocatalytic degradation experiment used $100 \mathrm{~mL}$ of RhB. Before the xenon lamp irradiation, stir the suspension for $0.5 \mathrm{~h}$ in the dark to reach the adsorption/desorption equilibrium of the photocatalyst surface. Take a small amount of solution every 15 min to measure the concentration of RhB during the photocatalytic degradation process. Since photo Fenton has a significant effect in degrading pollutants, the initial concentration of $\mathrm{RhB}$ in the photo Fenton degradation experiment is $10 \mathrm{mg} / \mathrm{L}$. The photo-Fenton experiment uses $100 \mathrm{~mL}$ $\mathrm{RhB}$, the initial concentration is $10 \mathrm{mg} / \mathrm{L}$, and the photocatalyst is $0.01 \mathrm{~g}$. Adjust the initial $\mathrm{pH}$ of the dye solution by using $0.1 \mathrm{M}$ sulfuric acid and $0.1 \mathrm{M}$ sodium hydroxide. At the same time, the catalyst was added to the RhB solution, and stirring was continued for $30 \mathrm{~min}$ to reach the absorption-desorption equilibrium. Subsequently, $\mathrm{H}_{2} \mathrm{O}_{2}$ was added, and visible light was irradiated on the suspension immediately. Take out a small amount of solution every $5 \mathrm{~min}$ to measure the concentration of RhB. Use 
a visible spectrophotometer $(\lambda=554 \mathrm{~nm})$ to test the absorbance of the solution. The Lambert-Beer law defines the degradation rate: $\left(C_{t}-C_{0}\right) / C_{0} \times 100 \%=\left(A_{0}-A_{t}\right) / A_{0} \times 100 \%$, where $C_{0}$ represents the initial solution concentration, $C_{t}$ represents the concentration of the solution after time t. After exposure time $t, A_{0}$ and $A_{t}$ respectively is the corresponding absorbance of the solution. In the active species capture experiment (BQ), p-benzoquinone, ethylenediaminetetraacetic acid (EDTA) and isopropanol (IPA) were used as capture agents for $\cdot \mathrm{O}_{2}-\mathrm{h}^{+}$and $\cdot \mathrm{OH}$ respectively.

\section{Results And Discussion}

\subsection{XRD and morphology analysis}

Through X-ray diffraction (XRD) analysis, the pure ZFO sample showed 5 obvious characteristic diffraction peaks at $2 \theta=29.9,35.2,42.8,56.6$ and $62.1^{\circ}$, corresponding to ZFO (2 20$)$, (3 11 1), (1 00 ) , (5 11 ) and (4 40 ) crystal planes, which coincide with the diffraction peak positions of the ZFO JCPDS standard card (79-1150). The pure BOI sample has 5 distinct characteristic diffraction peaks at $2 \theta=29.7$, $31.7,45.5,51.5$ and $55.3^{\circ}$, corresponding to BOI (012), (110), (020), (114) and (122) crystal planes, which coincide with the diffraction peak positions of the BOI JCPDS standard card (PDF\#73-2062). The X-ray diffraction pattern of ZFO/BOI composite material shows that in addition to the significant diffraction peaks of $\mathrm{BOI}$, there are also ZFO diffraction peaks, and no impurity phase is observed, which indicates that ZFO and BOI have been successfully recombined.

Figure 2a shows the SEM image of pure ZFO. The hydrothermally synthesized ZFO has a uniform spherical structure. Fig. $2 \mathrm{~d}$ is the SEM image of the composite ZFO/BOI-2. It can be seen that the composite material is a flake $\mathrm{BOI}$ with uniformly attached ZFO pellets. Fig. $2 \mathrm{~b}$ shows the TEM image of the ZFO/BOI-2 sample. The structure composed of flakes and small balls can be observed, consistent with the SEM image of ZFO/BOI. It can be seen from the mark in Fig. $2 \mathrm{c}$ that the enlarged view of the circular area is Fig. $2 f$, and its lattice spacing is $0.25 \mathrm{~nm}$, which corresponds to the (311) crystal plane of ZFO. The enlarged view of the square area in Fig. $2 \mathrm{c}$ is Fig. $2 \mathrm{~g}$, and its lattice spacing is $0.28 \mathrm{~nm}$, which corresponds to the (110) crystal plane of BOI. Fig. 2e is a selected area of electron diffraction (SAED), showing a diffraction ring composed of many homogeneous and tiny crystals. The cyan diffraction rings represent the (2 20 ), ( $\left.\begin{array}{lll}3 & 1 & 1\end{array}\right),\left(\begin{array}{lll}5 & 1 & 1\end{array}\right)$ and (4 40 ) crystal planes of ZFO crystals, and the yellow diffraction

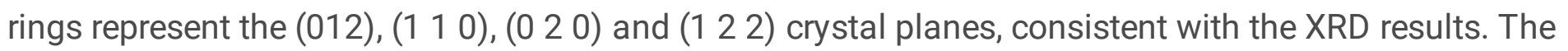
above results indicate the existence of binary composite ZFO/BOI. At the same time, there is a close relationship between ZFO and $\mathrm{BOI}$, forming a Z-scheme heterojunction, which is advantageous for separating photogenerated carriers.

Figure 3 shows the result of using the EDS test to determine the element types in the composite ZFO/BOI. Fig. $3 b-f$ can be seen the five elements of $\mathrm{O}, \mathrm{Zn}, \mathrm{Fe}, \mathrm{Bi}$ and I in the composite. It is not difficult to find from the EDS element distribution diagram that the distribution of each element is consistent with the shape of the composite material, which further proves that the composite material ZFO/BOI was successfully prepared without other impurities. 


\subsection{XPS and $\mathrm{N}_{2}$ adsorption-desorption}

We use XPS to study the elemental composition and chemical valence of ZFO/BOI-2 nanocomposites. Fig. 4 detects the peak signals of the six elements $\mathrm{C}, \mathrm{Zn}, \mathrm{Fe}, \mathrm{Bi}, \mathrm{O}$ and I in the ZFO/BOI-2 nanocomposite. The C1s spectrum (Fig. 4a) fits three peaks at 585.3, 586.8 and $589.2 \mathrm{eV}$, respectively, which indicates that the carbon species in this sample has three different chemical environments. The binding energy (BE) of $285.3 \mathrm{eV}$ coincides with -C-C and is identified as graphite or adventitious carbon. The peak at $286.8 \mathrm{eV}$ is designated to be embedded in the $\mathrm{C}-\mathrm{O}$ bond in the interlayer compound. The peak close to $289.2 \mathrm{eV}$ indicates the presence of carbonate species $(\mathrm{C}=0)$. (Zeng et al. 2019) The peaks at 1045.2 and $1021.9 \mathrm{eV}$ in Fig. $4 \mathrm{~b}$ can be designated as the binding energies of $Z n 2 p_{1 / 2}$ and $Z n 2 p_{3 / 2}$, which are similar to the standard data of $\mathrm{Zn}^{2+}$.(Li et al. 2011) In the Fe 2p spectrum from 740 to $705 \mathrm{eV}$ (Fig. 4c), the two prominent peaks belonging to $\mathrm{Fe} 2 \mathrm{p}_{1 / 2}$ and $\mathrm{Fe} 2 \mathrm{p}_{3 / 2}$ appear at 725.8 and $711.9 \mathrm{eV}$, while the satellite peak of $\mathrm{Fe} 2 p_{3 / 2}$ is at $720 \mathrm{eV}$. The binding energy of $\mathrm{Fe} 2 \mathrm{p}_{2 / 3}$ is $710.9 \mathrm{eV}$, which matches the binding energy of $\mathrm{Fe} 2 \mathrm{p}_{2 / 3}$ in ZFO very well. Meanwhile, Fe $2 \mathrm{p}_{3 / 2}$ peaks can be deconvolved into two peaks located at 711.9 and $710.9 \mathrm{eV}$, allocated to octahedral and tetrahedral $\mathrm{Fe}^{3+}$, respectively. (Cai et al. 2016, Li et al. 2018b) According to Fig. 4d, the two typical peaks of $\mathrm{Bi} 4 \mathrm{f}$ are located at 159.6 and 164.9 $\mathrm{eV}$, and respectively, this finding confirmed that $\mathrm{Bi}^{3+}$ cations in $\mathrm{ZFO} / \mathrm{BO}$ composites correspond to $\mathrm{Bi}$ $4 f_{5 / 2}$ and Bi $4 f_{7 / 2}$, respectively.(Qiu et al. 2017, Yang et al. 2018) The 01s map (Fig. 4e) fitted three peaks at $530.2,531.5$ and $532.8 \mathrm{eV}$ respectively. The characteristic peak at $530.2 \mathrm{eV}$ was derived from the Bi-O bond of $\left\{\mathrm{Bi}_{2} \mathrm{O}_{2}\right\}^{2+}$ layer in $\mathrm{BOI}$, and the peak at $531.9 \mathrm{eV}$ was corresponding to the Fe-O bond in ZFO. The peak at $532.8 \mathrm{eV}$ corresponds to the characteristic peak of free oxygen or hydrated oxides on the sample surface.(Bai et al. 2019, Tian et al. 2020) Two peaks were observed at about 619.5 and $631 \mathrm{eV}$ corresponding to I $3 d_{5 / 2}$ and I $3 d_{3 / 2}$, respectively (Fig. $4 f$ ), which were attributable to the $\mathrm{I}^{-}$ion of BOI.(Li et al. 2018a) In addition, the above analysis indicated the presence of BOI and ZFO in the composite sample.

The specific surface area and pore size distribution of pure ZFO and ZFO/BOI-2 composites were studied by speed ratio surface and porosity analyzer. As shown in Fig. 5a, the nitrogen adsorption-desorption isotherms of pure ZFO and ZFO/BOI-2 photocatalysts are in the range of $0-1.0 \mathrm{P} / \mathrm{P}_{0}$, and there is an evident IV type $\mathrm{H}_{3}$ hysteric ring. The IV type $\mathrm{H}_{3}$ hysteric ring indicates that the sample has a mesoporous structure and is composed of flake nanoparticles,(Raza \&Faraz 2020) which is consistent with SEM and HRTEM. In addition, the specific surface areas of pure ZFO and ZFO/BOI-2 were 88.988 and $42.538 \mathrm{~m}^{2} / \mathrm{g}$, respectively, calculated by Brunauer-Emmett-Teller(BET) model. The corresponding pore size distribution of the samples was determined by the BJH method, and the average adsorption pore size of ZFO and ZFO/BOI-2 was 151.06 and $218.39 \AA$.

\subsection{Optical analysis}

The light absorption capacity of semiconductor materials has an important influence on the photocatalytic activity. We analyzed the spectral absorption range of the photocatalyst by UV-Vis 
absorption spectrum. Fig. 6 shows the UV-Vis absorption spectra of the nanomaterials in the $250-800 \mathrm{~nm}$ range. Compared with pure $\mathrm{BOI}$ samples, the absorption intensity of ZFO/BOI samples was significantly improved in the range of $600-800 \mathrm{~nm}$, and the absorption edge was redshifted. This indicates that the binary composite photocatalyst can enhance the response in the visible region. According to Fig. $6 \mathrm{~b}$, the Eg values of ZFO and BOI were 1.71 and $2.02 \mathrm{eV}$, respectively. The red shift of the Z-scheme heterojunction ZFO/BOI may be due to the synergy between the flake $\mathrm{BOI}$ and ZFO nanoparticles.

$\mathrm{PL}$ spectroscopy is an effective method to study the composite behaviour of photo charges generated by photocatalyst. The PL spectra of pure ZFO and ZFO/BOI nanocomposites are shown in Fig. 7. Pure ZFO and ZFO/BOI nanocomposites show a luminescence peak at $505 \mathrm{~nm}$. The luminescence intensity of $\mathrm{ZFO} / \mathrm{BOI}$ nanocomposites is lower than that of pure ZFO, and the luminescence peak intensity of ZFO/BOI-2 is the lowest. The recombination rate of photogenerated carriers is the lowest. ZFO nanoparticles were modified on the surface of the flake $\mathrm{BOI}$ nanostructures to construct the ZFO/BOI heterojunction and the recombination rate of photogenerated carriers could be effectively reduced. However, when the content of $\mathrm{BOI}$ in $\mathrm{ZFO} / \mathrm{BO}$ is too high, many electron-hole pairs will recombine on the surface of BOI.

As shown in Fig. 8, the characteristic peaks located at $3445 \mathrm{~cm}^{-1}$ and $1626 \mathrm{~cm}^{-1}$ are respectively the $0-\mathrm{H}$ bond stretching vibration peaks and $\mathrm{H}-\mathrm{O}-\mathrm{H}$.(Yosefi et al. 2017) In addition, the vibration mode corresponding to $\mathrm{CH}_{3}$-bending was detected at $1383 \mathrm{~cm}^{-1}$. (Tamaddon et al. 2020) For pure BOI, the absorption peak located at $500 \mathrm{~cm}^{-1}$ is derived from the stretching vibration of the Bi-O bond.(Zhou et al. 2017) In addition, for the spinel ZFO sample, the A position is mainly occupied by $\mathrm{Zn}^{2+}$, and $\mathrm{Fe}^{3+}$ mainly occupies the $B$ position. The characteristic peaks located at $571 \mathrm{~cm}^{-1}$ and $418 \mathrm{~cm}^{-1}$ correspond to the stretching vibrations of the $\mathrm{Zn}-\mathrm{O}$ and $\mathrm{Fe}-\mathrm{O}$ bonds in the tetrahedral and octahedral positions, respectively. (Khasevani \&Gholami 2019)

\section{4. photo electrochemical properties analysis}

The CB and VB potentials of ZFO and BOI were determined by Mott-Schottky (M-S) plots. By extrapolating the linear part of the M-S plots to the horizontal axis. The slope of the M-S plot of ZFO is positive, indicating that it is an n-type semiconductor. That of $\mathrm{BO}$ is negative, showing as a p-type semiconductor. According to $\mathrm{V}(\mathrm{NHE})=\mathrm{V}(\mathrm{SCE})+0.059 \mathrm{pH}+0.242(\mathrm{pH}=7)$,(Huang et al. 2021) the relative standard calomel electrode (vs SCE) potential is converted to the standard hydrogen electrode (vs NHE) potential. It can be seen from Fig. 9a that the V(SCE) of ZFO is $-1.21 \mathrm{~V}$, the $\mathrm{V}(\mathrm{SCE})$ of $\mathrm{BOI}$ is $1.07 \mathrm{~V}$. It is generally believed that the VB edge potential of $p$-type semiconductors and the $C B$ edge potential of $n$-type semiconductors can be approximately equal to the VFB of semiconductors. Since ZFO is an n-type semiconductor, the conduction band potential of $\mathrm{ZFO}$ is $\mathrm{V}_{\mathrm{CB}}=\mathrm{V}(\mathrm{NHE})=-0.55 \mathrm{~V}$. The valence band potential of $\mathrm{BOI}$ is $\mathrm{V}_{\mathrm{VB}}=\mathrm{V}(\mathrm{NHE})=1.72 \mathrm{~V}$ because $\mathrm{BO}$ is a p-type semiconductor.

EIS impedance spectroscopy and transient photocurrent test research were carried out to understand the photo-Fenton mechanism in-depth. Fig. 10a shows that the EIS of nanomaterials is approximately 
semicircle in the high-frequency region. The semicircle diameter of ZFO/BOI composite in the highfrequency region is smaller than that of pure $\mathrm{ZFO}$ and $\mathrm{BOI}$, which indicates that it has a low charge transfer resistance. The results show that the ZFO/BOI heterojunction can significantly improve photogenerated electron-hole pairs' separation and migration efficiency. Fig. 10b shows the transient photocurrent response of the sample in five cycles of on/off under simulated sunlight. The photocurrent densities of ZFO, BOI, ZFO/BOI-1, ZFO/BOI-2 and ZFO/BOI-3 photocatalysts were $5.82 \times 10^{-8}, 1.34 \times 10^{-7}$, $1.27 \times 10^{-6}, 1.71 \times 10^{-6}$ and $6.5 \times 10^{-7} \mathrm{~mA} / \mathrm{cm}^{2}$,respectively. After the light is turned off, the photocurrent is reduced to the initial value. Compared with pure ZFO and $\mathrm{BOI}$, the photocurrent density of ZFO/BOI-2 heterojunction is significantly increased, indicating that the photogenerated carriers of ZFO/BOI-2 heterojunction can be separated and migrated more effectively. By comparing the EIS and transient photocurrent responses of pure and composite photocatalysts, the ZFO/BOI nanocomposites showed better-photogenerated charge separation and migration ability, which indicated that the ZFO/BOI heterojunction composite photocatalyst might have better Fenton activity.

\subsection{Photo-Fenton analysisis}

The photo-Fenton activity of ZFO/BOI heterojunction was tested by dissolving RhB in simulated solar degradation. Fig. 11a shows the degradation rates of photo-Fenton degradation of RhB by pure ZFO, BOI and ZFO/BOI nanocomposites with different composite ratios. Under the action of photocatalytic degradation, the concentration of $\mathrm{RhB}$ dye decreases with the increase of the illumination time. Under the illumination condition of $90 \mathrm{~min}, \mathrm{ZFO}, \mathrm{BOI}, \mathrm{ZFO} / \mathrm{BOI}-1, \mathrm{ZFO} / \mathrm{BOI}-2$ and ZFO/BOI-3 nanocomposites had degradation rates of $27.5,58.9,84.1,88.6$ and $78.1 \%$, respectively. In Fig. 11c, the degradation rates of ZFO, BOI, ZFO/BOI-1, ZFO/BOI-2 and ZFO/BOI-3 nanocomposites were 24.3, 51.9, 96.9, 100 and 94.6\%, respectively, under the light condition of only $20 \mathrm{~min}$. The photo-Fenton degradation rate of ZFO/BOI heterojunction was significantly higher than that of pure ZFO and $\mathrm{BOI}$, and the photo-Fenton activity of ZFO/BOI-2 was the strongest. The excellent photonic Fenton properties of ZFO/BOI nanocomposites are since highly dispersed ZFO particles are uniformly distributed on the surface of the sheets of $\mathrm{BOI}$ and fully contact to form a ZFO/BOI heterojunction. ZFO/BOI heterojunction can enhance the visible light absorption capacity. Moreover, this novel ZFO/BOI heterojunction can promote the migration and separation of photogenerated carriers and inhibit their recombination, thus improving the photo-Fenton degradation ability. Through the first-order kinetic model equation: $\ln \left(C_{t} / C_{0}\right)=-K_{a p p} t$, the kinetics characteristics of the degradation of $\mathrm{RhB}$ by ZFO/BOI heterojunction photo-Fenton can be quantitatively studied, where $\mathrm{K}_{\mathrm{app}}$ is the first-order kinetic reaction rate, and $\mathrm{C}$ is the concentration of RhB dye. Fig. 11b is ZFO/BOI photocatalytic degradation of corresponding first-order kinetics curves of ZFO, BOI, ZFO/BOI1 , and $\mathrm{ZFO} / \mathrm{BOI}-2, \mathrm{ZFO} / \mathrm{BOI}-3$ samples of the reaction rate constant $\mathrm{K}_{\mathrm{app}}$ were $0.0025,0.0083,0.016$, 0.021 and $0.015 \mathrm{~min}^{-1}$. Fig. $11 \mathrm{~d}$ is Fenton $\mathrm{ZFO} / \mathrm{BO}$ light degradation of corresponding first-order kinetics curve, ZFO, BOI, ZFO/BOI-1, ZFO/BOI-2, and ZFO/BOI-3 samples of the reaction rate constant $\mathrm{K}_{\mathrm{app}}$ were $0.0147,0.0857,0.1518,0.4008$ and $0.1404 \mathrm{~min}^{-1}$. The $\mathrm{K}_{\mathrm{app}}$ value of $\mathrm{ZFO} / \mathrm{BO}-2$ was the highest in the composite sample, indicating that the photo-Fenton degradation rate of ZFO/BOI-2 was the highest, and the photo-Fenton degradation rate was about 19 times that of the photocatalytic degradation rate. As the 
amount of $\mathrm{BOI}$ increases, $\mathrm{K}_{\mathrm{app}}$ first increases and then decreases. A part of photogenerated carriers will recombine on the $\mathrm{BOI}$ surface because when the $\mathrm{BOI}$ content in $\mathrm{ZFO} / \mathrm{BO}$ is too high.

Test the active species of ZFO/BOI-2 photo-Fenton to degrade RhB through the dynamic species capture experiment, using ethylenediaminetetraacetic acid (EDTA), p-benzoquinone (BQ) and isopropyl alcohol (IPA) to capture $\mathrm{h}^{+}, \mathrm{O}_{2}$ - and $\cdot \mathrm{OH}$. The illustration in Fig. 12 shows the degradation of RhB over time in the ZFO/BOI-2 sample after adding different capture agents. The degradation rate decreased when EDTA or $\mathrm{BQ}$ was added. The photocatalytic degradation rate of ZFO/BOI-2 samples decreased significantly after adding IPA, indicating that shows that $\cdot \mathrm{OH}$ is the main active substance. The role of $\cdot \mathrm{O}_{2}$ - and $\mathrm{h}^{+}$in the degradation of photo-Fenton is relatively weak.

Repeated cyclic tests investigated the stability of ZFO/BOI-2 nanomaterials under the same environment. In Fig. 13, the first degradation rate of the catalyst was $100 \%$ after 25 min. Although the degradation rate decreases slightly with the number of cycles, the degradation rate can still reach $81.6 \%$ after three cycles, indicating that the cycling stability of ZFO/BOI-2 composite material is good. The ZFO/BOI photocatalyst can be recovered by an external magnetic field due to the ferromagnetic nature of ZFO. ZFO/BOI photocatalyst shows good stability and reproducibility in RhB degradation, which can be used in the actual dye wastewater purification.

\subsection{Possible mechanism}

It is proposed that the carrier migration mode of Z-scheme heterojunction ZFO/BOI (Fig. 14) is generated because $\mathrm{BOI}$ and ZFO absorb enough energy photons to excite electron transition from the valence band to the conduction band. The valence band and conduction band of $\mathrm{BOI}$ are lower than that of $\mathrm{ZFO}$, and the photoelectrons in the conduction band of $\mathrm{BOI}$ can migrate to the valence band of ZFO to recombine with $\mathrm{h}^{+}$. The remaining carriers undergo redox reactions in the valence band of ZFO and the conduction band of $\mathrm{BOI}$, respectively. In the process of photo-Fenton degradation, $\mathrm{e}^{-}$of ZFO conduction band reacts with $\mathrm{O}_{2}$ in water to generate $\cdot \mathrm{O}_{2}$ - In addition, because of the strong oxidation of $\mathrm{h}^{+}$, part of it can directly degrade $\mathrm{RhB}$, a small part $\mathrm{h}^{+}$can react with $\mathrm{OH}$ - to form $\cdot \mathrm{OH}$. The simplified possible reaction of generating hydroxyl radicals in the process of adding hydrogen peroxide to the acidic solution is determined by $r_{1}$ and $r_{2}$, as shown below:

$\mathrm{Fe}^{3+}+\mathrm{hv}+\mathrm{H}_{2} \mathrm{O} \rightarrow \mathrm{Fe}^{2+}+\cdot \mathrm{OH}+\mathrm{H}^{+}\left(\mathrm{r}_{1}\right)$

$\mathrm{Fe}^{2+}+\mathrm{H}_{2} \mathrm{O}_{2} \rightarrow \mathrm{Fe}^{3+}+\cdot \mathrm{OH}+\mathrm{OH}-\left(\mathrm{r}_{2}\right)$

$\cdot \mathrm{O}_{2}, \mathrm{~h}^{+}$and $\cdot \mathrm{OH}$ radicals produced in the photo-Fenton reaction degrades $\mathrm{RhB}$ dye into $\mathrm{H}_{2} \mathrm{O}, \mathrm{CO}_{2}$ and small molecule substances. This is consistent with the above capture experiment results. Therefore, Zscheme heterojunction ZFO/BOI construction has a noticeable effect on inhibiting the recombination of photo-generated charges and can also improve carriers' transport and separation efficiency. The photoFenton process helps to strengthen its economic and environmental sustainability. 


\section{Conclusions}

A series of magnetically separable Z-type heterojunction composite materials with different BOI content were successfully prepared by hydrothermal and subsequent co-precipitation methods. The prepared catalyst shows excellent degradation performance and sufficient magnetic properties for the degradation of RhB under simulated sunlight irradiation. It can be reused in the photo-Fenton process, especially ZFO/BOI-2. Optical analysis and photoelectrochemical analysis indicate that the improved RhB removal efficiency of $\mathrm{ZFO} / \mathrm{BOI}-2$ may be attributed to the synergy between $\mathrm{ZnFe}_{2} \mathrm{O}_{4}$ and $\mathrm{BiOl}$, which may lead to effective electron-hole pair separation. The trapping experiment results show that $\cdot \mathrm{OH}$ radicals are the main reaction substances that promote the oxidation and reduction of the photo-Fenton process. This work can understand the process of using magnetic catalysts to degrade pollutants under sunlight.

\section{Declarations}

Ethics approval Not applicable.

Consent to participate Not applicable.

Consent for publication All authors agree to publish.

Availability of data and materials Not applicable.

Competing interests The authors declare no competing interests.

Funding This work was supported by the National Natural Science Foundation of China (51261015).

Authors' contributions Chao Li provides conceptualization, methodology, software, review, editing and verification. Zhiqiang Wei analyzed and explained the relevant photo-Fenton data. Qiang Lu provides some tests. Jinhuan Ma and Ling Li provide some ideas in writing the manuscript. Final manuscript read and approved by all authors.

Acknowledgements The author thanks the supervisor for supporting this work, and the author also thanks the students of the research group for their help.

\section{References}

1. Bai Y, Bai H, Qu K, Wang F, Guan P, Xu D, Fan W, Shi W (2019): In-situ approach to fabricate BiOI photocathode with oxygen vacancies: Understanding the $\mathrm{N}_{2}$ reduced behavior in photoelectrochemical system. Chemical Engineering Journal 362, 349-356

2. Behera A, Mansingh S, Das KK, Parida K (2019): Synergistic $\mathrm{ZnFe}_{2} \mathrm{O}_{4}$-carbon allotropes nanocomposite photocatalyst for norfloxacin degradation and $\mathrm{Cr}(\mathrm{VI})$ reduction. J Colloid Interface Sci 544, 96-111 
3. Cai C, Zhang Z, Liu J, Shan N, Zhang H, Dionysiou DD (2016): Visible light-assisted heterogeneous Fenton with $\mathrm{ZnFe}_{2} \mathrm{O}_{4}$ for the degradation of Orange II in water. Applied Catalysis B: Environmental $182,456-468$

4. Chen $\mathrm{C}-\mathrm{H}$, Liang $\mathrm{Y}-\mathrm{H}$, Zhang W-D (2010): $\mathrm{ZnFe}_{2} \mathrm{O}_{4} / \mathrm{MWCNTs}$ composite with enhanced photocatalytic activity under visible-light irradiation. Journal of Alloys and Compounds 501, 168-172

5. Chen F, Yang Q, Wang Y, Yao F, Ma Y, Huang X, Li X, Wang D, Zeng G, Yu H (2018): Efficient construction of bismuth vanadate-based Z-scheme photocatalyst for simultaneous $\mathrm{Cr}(\mathrm{VI})$ reduction and ciprofloxacin oxidation under visible light: Kinetics, degradation pathways and mechanism. Chemical Engineering Journal 348, 157-170

6. Chen $\mathrm{P}$, Zhang N, Chen W, Wang Y (2021): Rhombic $\mathrm{Fe}_{2} \mathrm{O}_{3}$ lumps doping hollow $\mathrm{ZnFe}_{2} \mathrm{O}_{4}$ spheres through oxidative decomposition process implanted into graphene conductive network with superior electromagnetic wave absorption properties. Ceramics International 47, 6453-6462

7. Clarizia L, Russo D, Di Somma I, Marotta R, Andreozzi R (2017): Homogeneous photo-Fenton processes at near neutral pH: A review. Applied Catalysis B-Environmental 209, 358-371

8. Guo Q, Ma Z, Zhou C, Ren Z, Yang X (2019a): Single Molecule Photocatalysis on $\mathrm{TiO}_{2}$ Surfaces. Chem Rev 119, 11020-11041

9. Guo Q, Zhou C, Ma Z, Yang X (2019b): Fundamentals of $\mathrm{TiO}_{2}$ Photocatalysis: Concepts, Mechanisms, and Challenges. Adv Mater 31, e1901997

10. Hasija V, Raizada P, Sudhaik A, Sharma K, Kumar A, Singh P, Jonnalagadda SB, Thakur VK (2019): Recent advances in noble metal free doped graphitic carbon nitride based nanohybrids for photocatalysis of organic contaminants in water: A review. Applied Materials Today 15, 494-524

11. Hu J, Zhang P, An W, Liu L, Liang Y, Cui W (2019): In-situ Fe-doped g- $C_{3} N_{4}$ heterogeneous catalyst via photocatalysis-Fenton reaction with enriched photocatalytic performance for removal of complex wastewater. Applied Catalysis B-Environmental 245, 130-142

12. Huang D, Hu C, Zeng G, Cheng M, Xu P, Gong X, Wang R, Xue W (2017): Combination of Fenton processes and biotreatment for wastewater treatment and soil remediation. Science of the Total Environment 574, 1599-1610

13. Huang S, Wei Z, Ding M, Li C, Lu Q (2021): Photo-electrochemical and photocatalytic properties of hierarchical flower-like $\mathrm{BiOl} / \mathrm{CoFe} \mathrm{O}_{4}$ nanocomposites synthesized by co-precipitation method. Optical Materials 111

14. Jiang L, Gao W, Jin B, Li H, Li S, Zhu G, Jiang Q (2018): $\mathrm{ZnFe}_{2} \mathrm{O}_{4} / \mathrm{MoS}_{2} / \mathrm{rGO}$ composite as an anode for rechargeable Lithium-ion batteries. Journal of Electroanalytical Chemistry 823, 407-415

15. Khasevani SG, Gholami MR (2019): Synthesis of $\mathrm{BiOI} / \mathrm{ZnFe}_{2} \mathrm{O}_{4}-$ Metal-Organic Framework and g$\mathrm{C}_{3} \mathrm{~N}_{4}$-Based Nanocomposites for Applications in Photocatalysis. Industrial \& Engineering Chemistry Research 58, 9806-9818

16. Li C, Zhang A, Zhang L, Song J, Su S, Sun Z, Xiang J (2018a): Enhanced photocatalytic activity and characterization of magnetic $\mathrm{Ag} / \mathrm{BiOl} / \mathrm{ZnFe}_{2} \mathrm{O}_{4}$ composites for $\mathrm{Hg} 0$ removal under fluorescent light 
irradiation. Applied Surface Science 433, 914-926

17. Li X, Hou Y, Zhao Q, Wang L (2011): A general, one-step and template-free synthesis of sphere-like zinc ferrite nanostructures with enhanced photocatalytic activity for dye degradation. J Colloid Interface Sci 358, 102-8

18. Li Z, Chen H, Liu W (2018b): Full-Spectrum Photocatalytic Activity of $\mathrm{ZnO} / \mathrm{CuO} / \mathrm{ZnFe}_{2} \mathrm{O}_{4}$ Nanocomposite as a PhotoFenton-Like Catalyst. Catalysts 8

19. Liu Y, Jin W, Zhao Y, Zhang G, Zhang W (2017): Enhanced catalytic degradation of methylene blue by alpha- $\mathrm{Fe}_{2} \mathrm{O}_{3} /$ graphene oxide via heterogeneous photo-Fenton reactions. Applied Catalysis BEnvironmental 206, 642-652

20. Meng A, Zhang L, Cheng B, Yu J (2019): Dual Cocatalysts in $\mathrm{TiO}_{2}$ Photocatalysis. Adv Mater 31, e1807660

21. Mirzaei A, Chen Z, Haghighat F, Yerushalmi L (2017): Removal of pharmaceuticals from water by homo/heterogonous Fenton-type processes - A review. Chemosphere 174, 665-688

22. Qiu F, Li W, Wang F, Li H, Liu X, Sun J (2017): In-situ synthesis of novel Z-scheme SnS(2)/BiOBr photocatalysts with superior photocatalytic efficiency under visible light. J Colloid Interface Sci 493, $1-9$

23. Raza W, Faraz M (2020): Novel g- $\mathrm{C}_{3} \mathrm{~N}_{4} / \mathrm{Fe}-\mathrm{ZnO} / \mathrm{RGO}$ nanocomposites with boosting visible light photocatalytic activity for $\mathrm{MB}, \mathrm{Cr}(\mathrm{VI})$, and outstanding catalytic activity toward para-nitrophenol reduction. Nanotechnology 31, 325603

24. Sharma VK, Feng M (2019): Water depollution using metal-organic frameworks-catalyzed advanced oxidation processes: A review. Journal of Hazardous Materials 372, 3-16

25. Tamaddon F, Mosslemin MH, Asadipour A, Gharaghani MA, Nasiri A (2020): Microwave-assisted preparation of $\mathrm{ZnFe}_{2} \mathrm{O}_{4} @$ @methyl cellulose as a new nano-biomagnetic photocatalyst for photodegradation of metronidazole. Int J Biol Macromol 154, 1036-1049

26. Tian $N$, Huang $H$, Wang S, Zhang T, Du $X$, Zhang $Y$ (2020): Facet-charge-induced coupling dependent interfacial photocharge separation: $\mathrm{A}$ case of $\mathrm{BiOl} / \mathrm{g}-\mathrm{C}_{3} \mathrm{~N}_{4} \mathrm{p}-\mathrm{n}$ junction. Applied Catalysis $\mathrm{B}$ : Environmental 267

27. Wu H, Jile H, Chen Z, Xu D, Yi Z, Chen X, Chen J, Yao W, Wu P, Yi Y (2020): Fabrication of ZnO@MoS Nanocomposite Heterojunction Arrays and Their Photoelectric Properties. Micromachines (Basel) 11

28. Xiang Y, Huang Y, Xiao B, Wu X, Zhang G (2020): Magnetic yolk-shell structure of $\mathrm{ZnFe}_{2} \mathrm{O}_{4}$ nanoparticles for enhanced visible light photo-Fenton degradation towards antibiotics and mechanism study. Applied Surface Science 513

29. Xing M, Xu W, Dong C, Bai Y, Zeng J, Zhou Y, Zhang J, Yin Y (2018): Metal Sulfides as Excellent Cocatalysts for $\mathrm{H}_{2} \mathrm{O}_{2}$ Decomposition in Advanced Oxidation Processes. Chem 4, 1359-1372

30. Yang Y, Zeng Z, Zhang C, Huang D, Zeng G, Xiao R, Lai C, Zhou C, Guo H, Xue W, Cheng M, Wang W, Wang J (2018): Construction of iodine vacancy-rich BiOl/Ag@AgI Z-scheme heterojunction 
photocatalysts for visible-light-driven tetracycline degradation: Transformation pathways and mechanism insight. Chemical Engineering Journal 349, 808-821

31. Yang Y, Zeng G, Huang D, Zhang C, He D, Zhou C, Wang W, Xiong W, Li X, Li B, Dong W, Zhou Y (2020): Molecular engineering of polymeric carbon nitride for highly efficient photocatalytic oxytetracycline degradation and $\mathrm{H}_{2} \mathrm{O}_{2}$ production. Applied Catalysis B-Environmental 272

32. Yendrapati TP, Gautam A, Bojja S, Pal U (2020): Formation of ZnO@CuS nanorods for efficient photocatalytic hydrogen generation. Solar Energy 196, 540-548

33. Yosefi L, Haghighi M, Allahyari S (2017): Solvothermal synthesis of flowerlike p-BiOl/n- $\mathrm{ZnFe} \mathrm{O}_{4}$ with enhanced visible light driven nanophotocatalyst used in removal of acid orange 7 from wastewater. Separation and Purification Technology 178, 18-28

34. Zeng L, Zhe F, Wang Y, Zhang Q, Zhao X, Hu X, Wu Y, He Y (2019): Preparation of interstitial carbon doped $\mathrm{BiOl}$ for enhanced performance in photocatalytic nitrogen fixation and methyl orange degradation. J Colloid Interface Sci 539, 563-574

35. Zhang M-h, Dong H, Zhao L, Wang D-x, Meng D (2019): A review on Fenton process for organic wastewater treatment based on optimization perspective. Science of the Total Environment $670,110-$ 121

36. Zheng C, Zhang C, He L, Zhang K, Zhang J, Jin L, Asiri AM, Alamry KA, Chu X (2020): $\mathrm{ZnFe}_{2} \mathrm{O}_{4} / \mathrm{ZnO}$ nanosheets assembled microspheres for high performance trimethylamine gas sensing. Journal of Alloys and Compounds 849

37. Zhou J, Zhang Z, Kong X, He F, Zhao R, Wu R, Wei T, Wang L, Feng J (2020a): A novel P-N heterojunction with staggered energy level based on $\mathrm{ZnFe}_{2} \mathrm{O}_{4}$ decorating $\mathrm{SnS}_{2}$ nanosheet for efficient photocatalytic degradation. Applied Surface Science 510

38. Zhou Q, Li L, Xin Z, Yu Y, Wang L, Zhang W (2020b): Visible light response and heterostructure of composite CdS@ZnS-ZnO to enhance its photocatalytic activity. Journal of Alloys and Compounds 813

39. Zhou Y, Fang S, Zhou M, Wang G, Xue S, Li Z, Xu S, Yao C (2017): Fabrication of novel $\mathrm{ZnFe}_{2} \mathrm{O}_{4} / \mathrm{BiOl}$ nanocomposites and its efficient photocatalytic activity under visible-light irradiation. Journal of Alloys and Compounds 696, 353-361

\section{Figures}




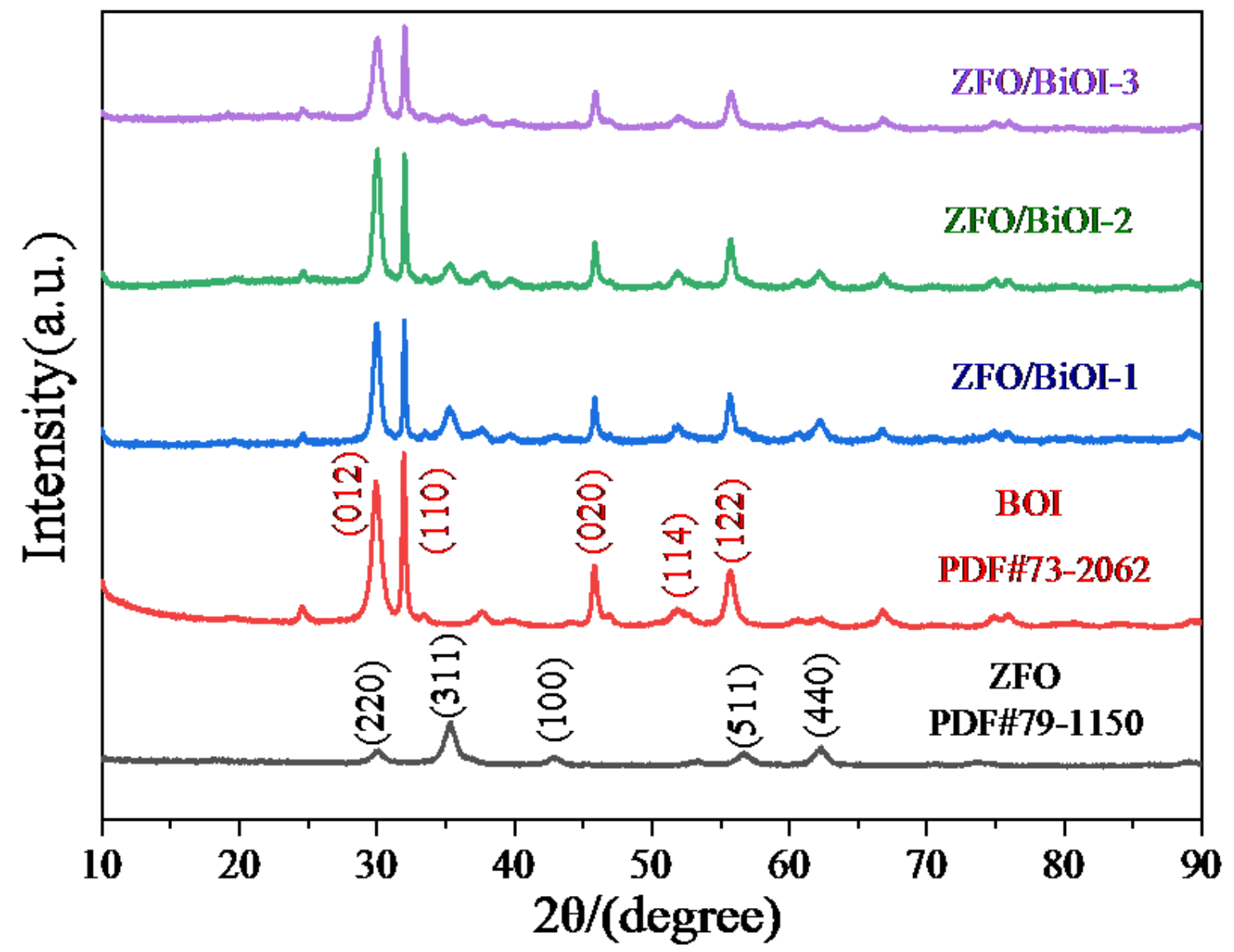

Figure 1

XRD patterns of ZFO, BOI and ZFO/BOI composites 


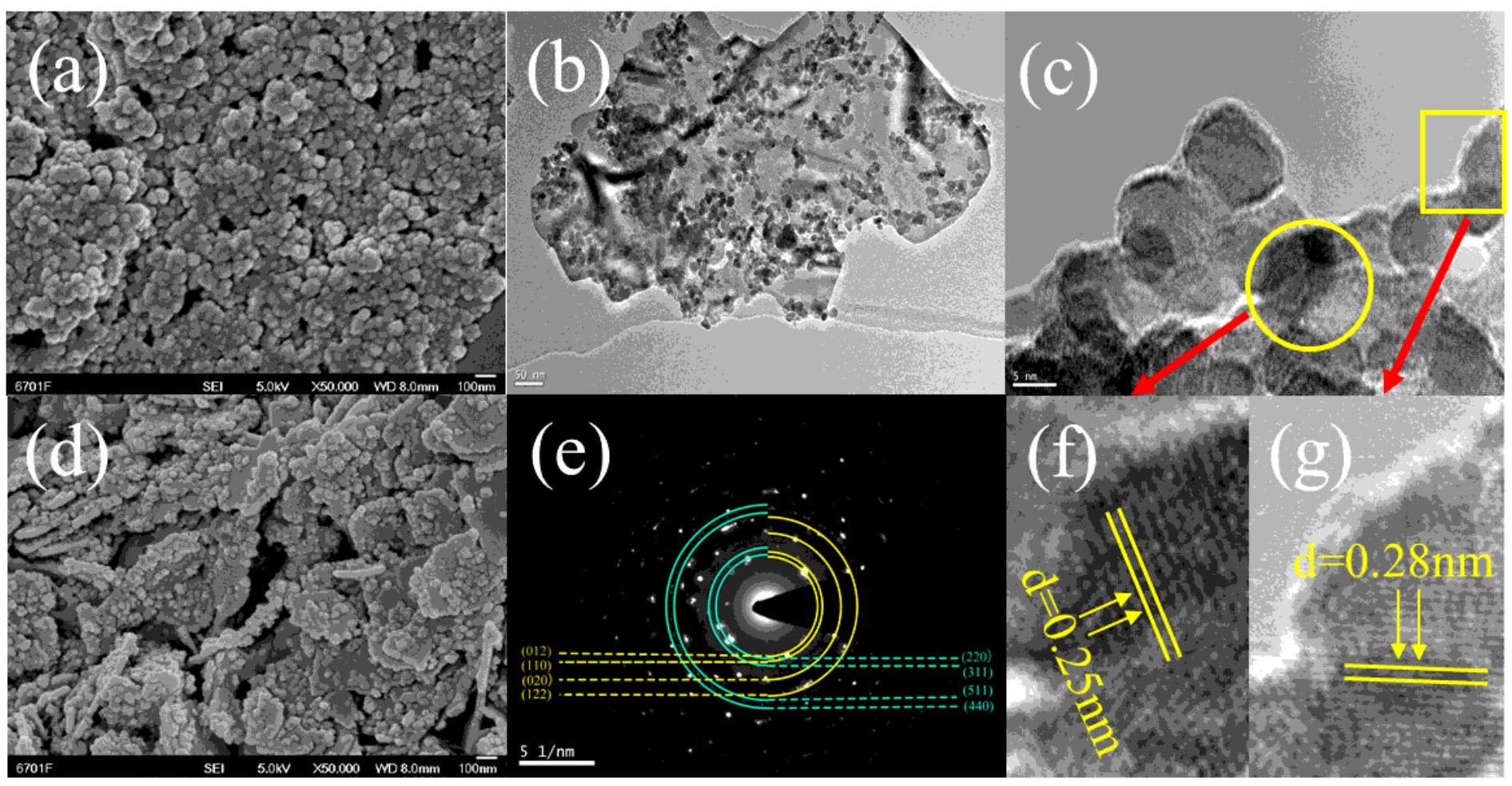

Figure 2

SEM images of (a) ZFO, (d) ZFO/BOI-2 and (b) TEM image and (c, f, g) HRTEM images and (e) SAED pattern of ZFO/BOI-2 composites 


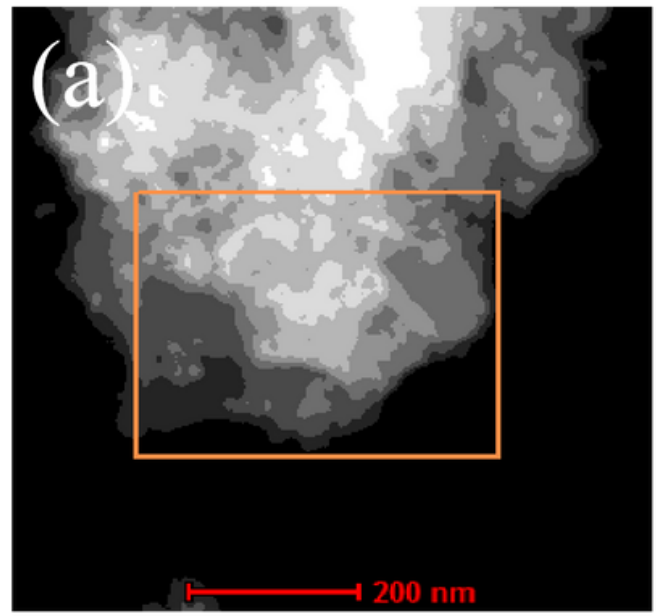

(b)

(c)

(d)

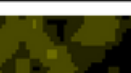

$y^{2}$

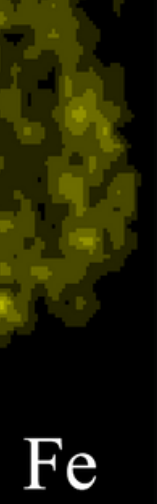

(e)

$\mathrm{O}$

$\mathrm{Zn}$

$+4+4$

$6+2$

$x^{2}+1$

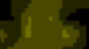

$x^{2}+4$
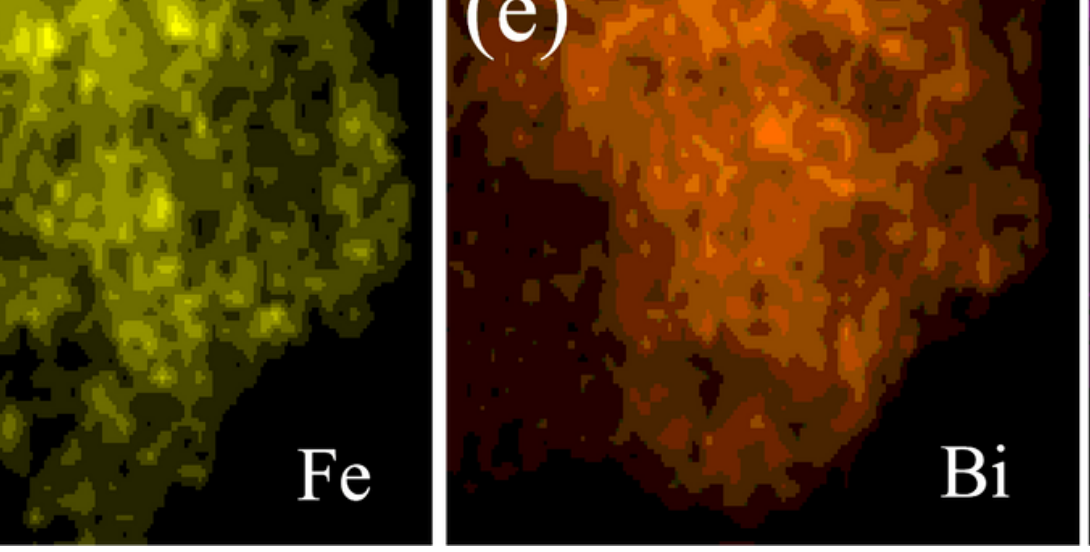

(f)

Figure 3

EDS elemental mapping images of ZFO/BOI-2 composites 

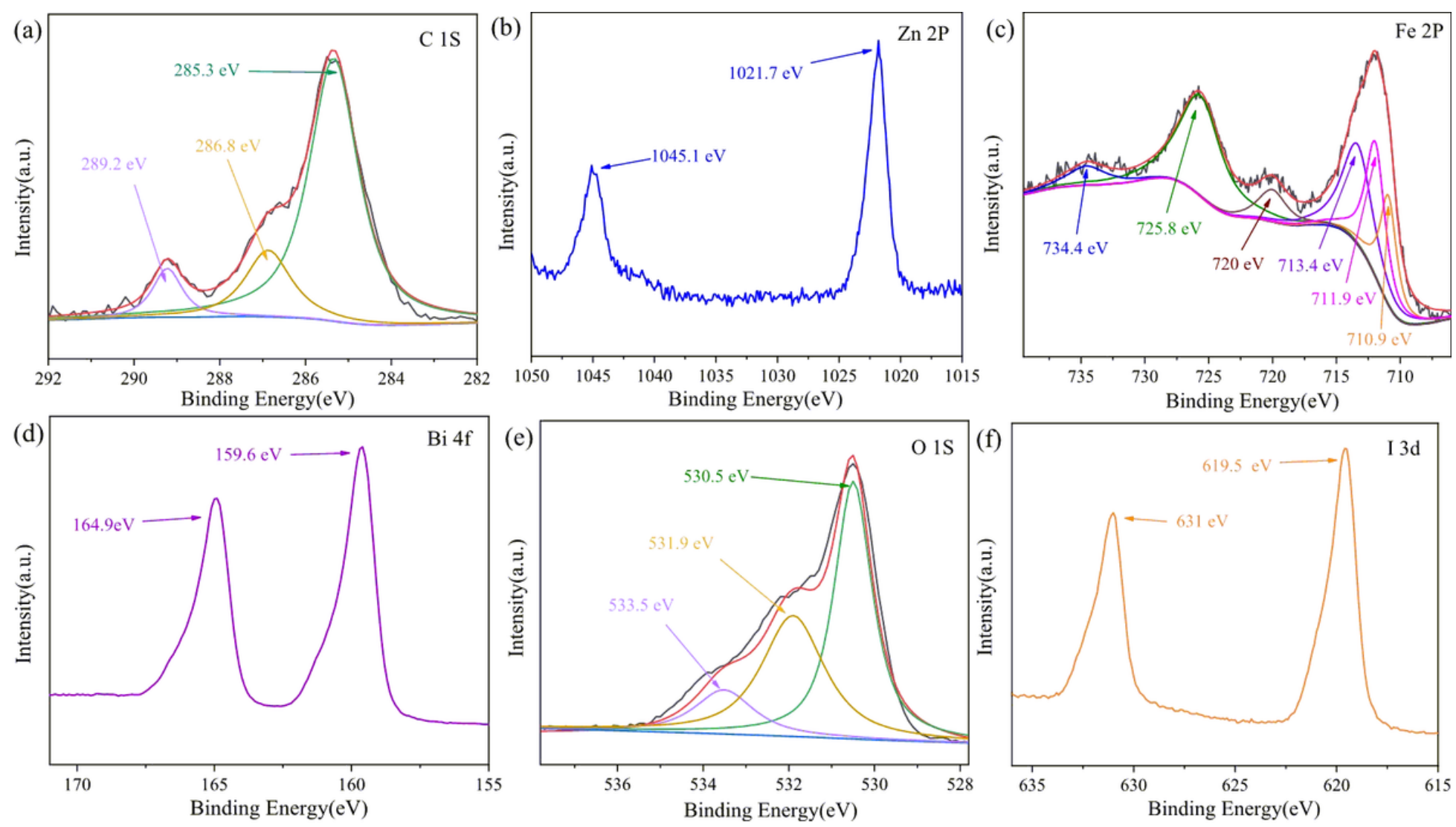

Figure 4

XPS spectrometer of ZFO/BOl-2 composites (a) C 1s, (b) Zn 2P, (c) Fe 2p, (d) Bi 4f, (e) 0 1s and (f) I 3d
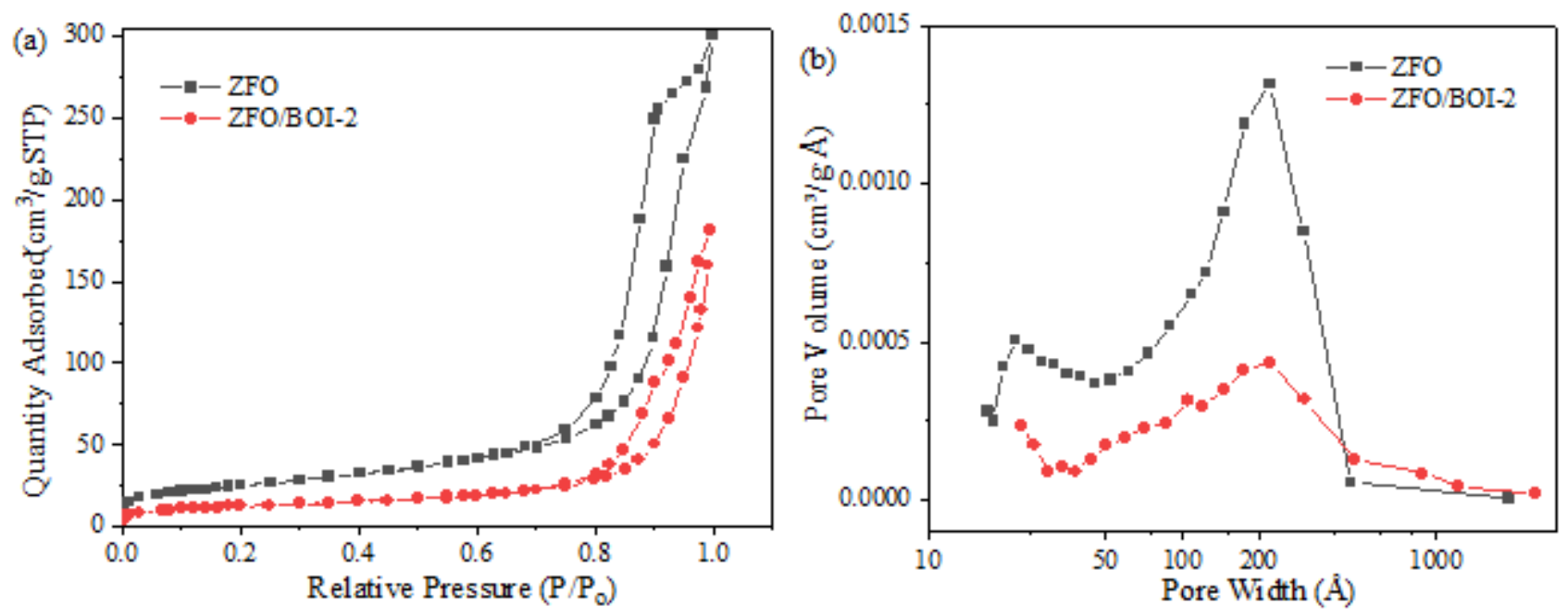

Figure 5 
(a) Nitrogen adsorption-desorption isotherms and (b) pore size distribution of ZFO and ZFO/BOI-2 composites
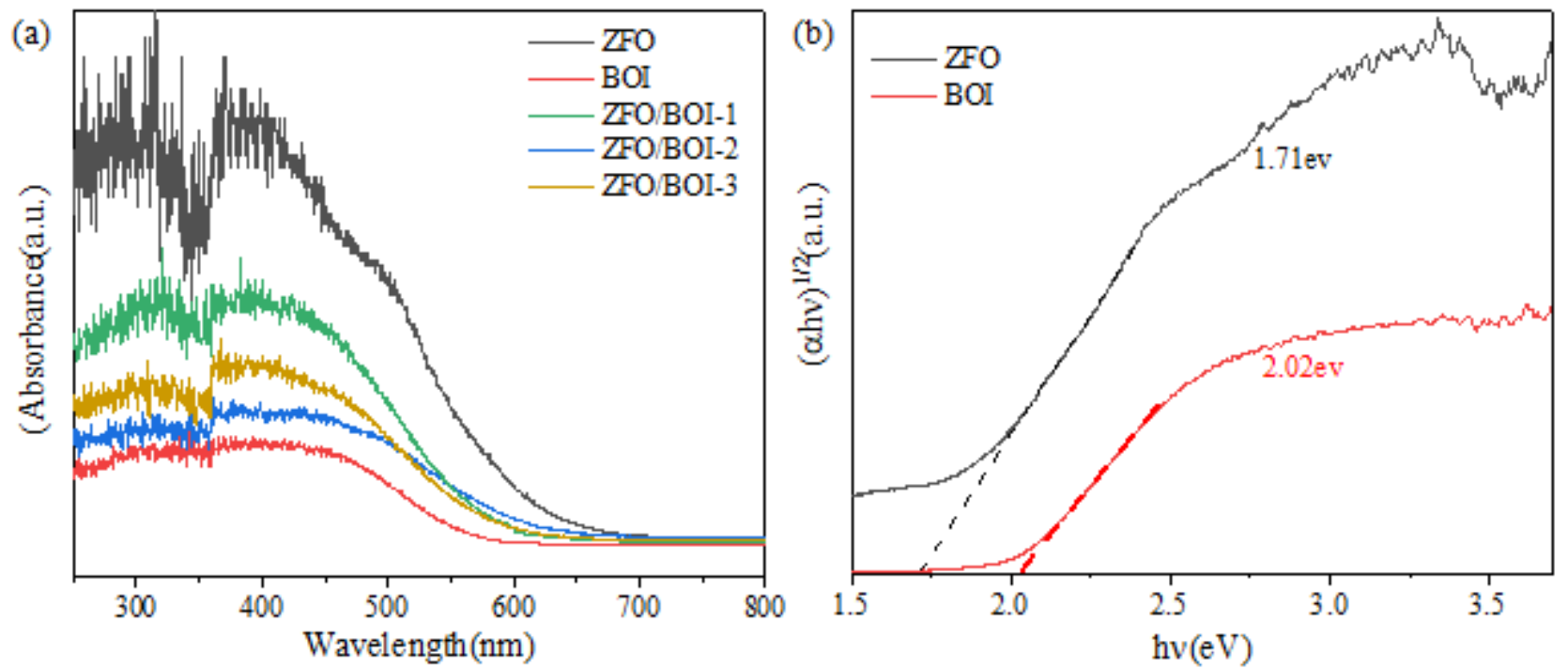

Figure 6

(a) UV-vis DRS spectra of ZFO, BOI and ZFO/BOI samples, (b) (ahv)n-hv curves

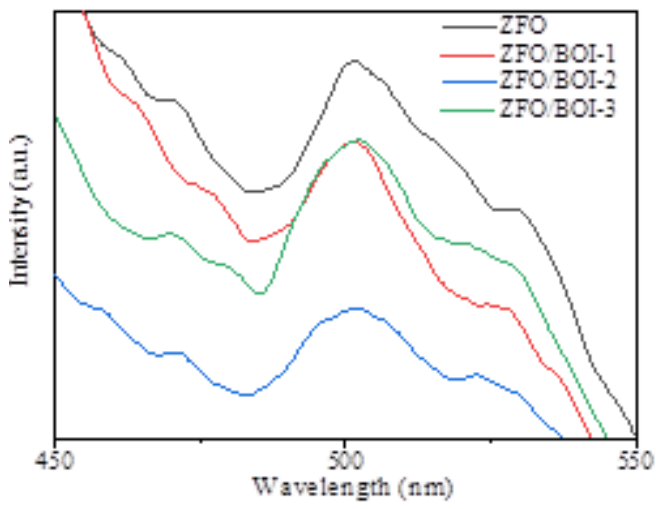

Figure 7

$\mathrm{PL}$ spectra of pure ZFO and ZFO/BOI -2 composites

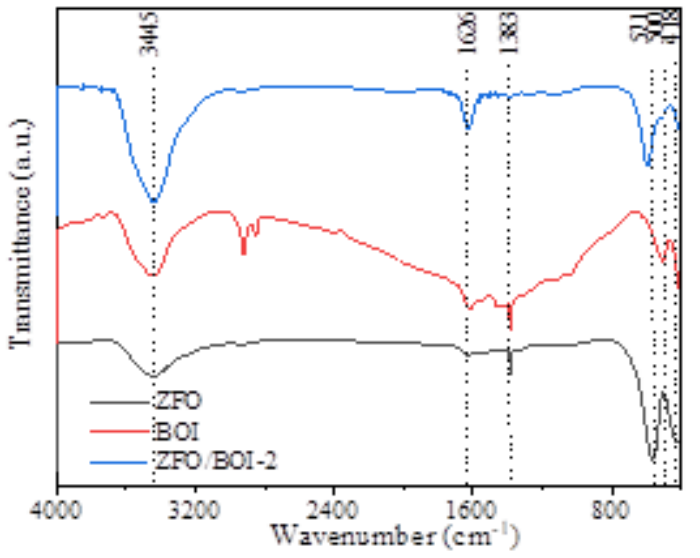


Figure 8

FT-IR spectroscopy of ZFO, BOI and ZFO/BOI -2 samples
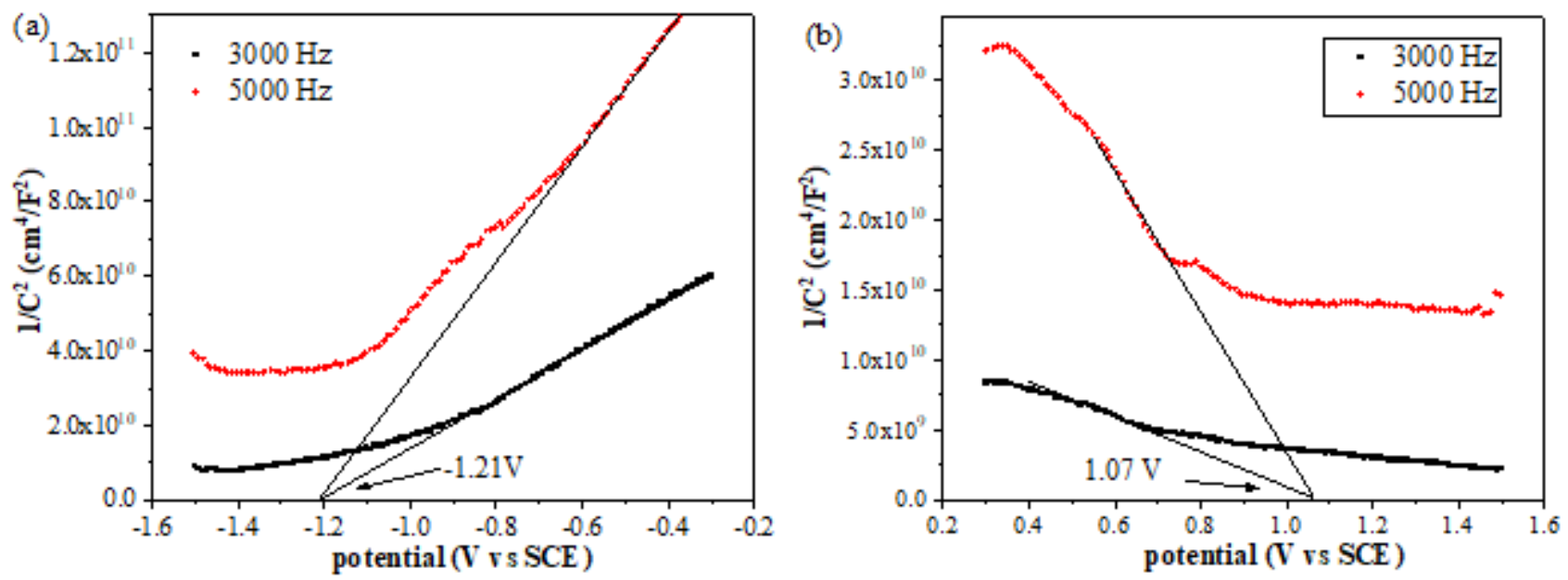

Figure 9

M-S plots of (a) ZFO and (b) BOI samples
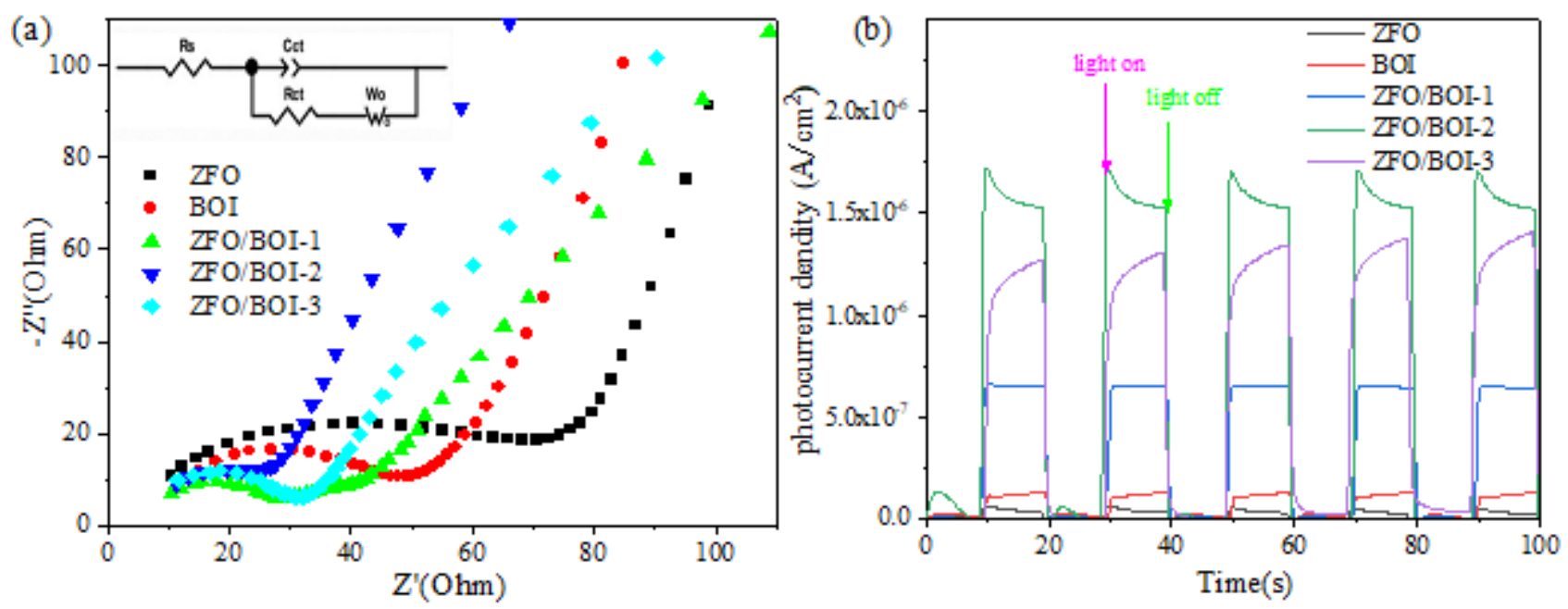

Figure 10

(a) Electrochemical impedance spectroscopy Nyquist plots and (b) transient photocurrent responses of pure ZFO, BOI and ZFO/BOI -2 samples 

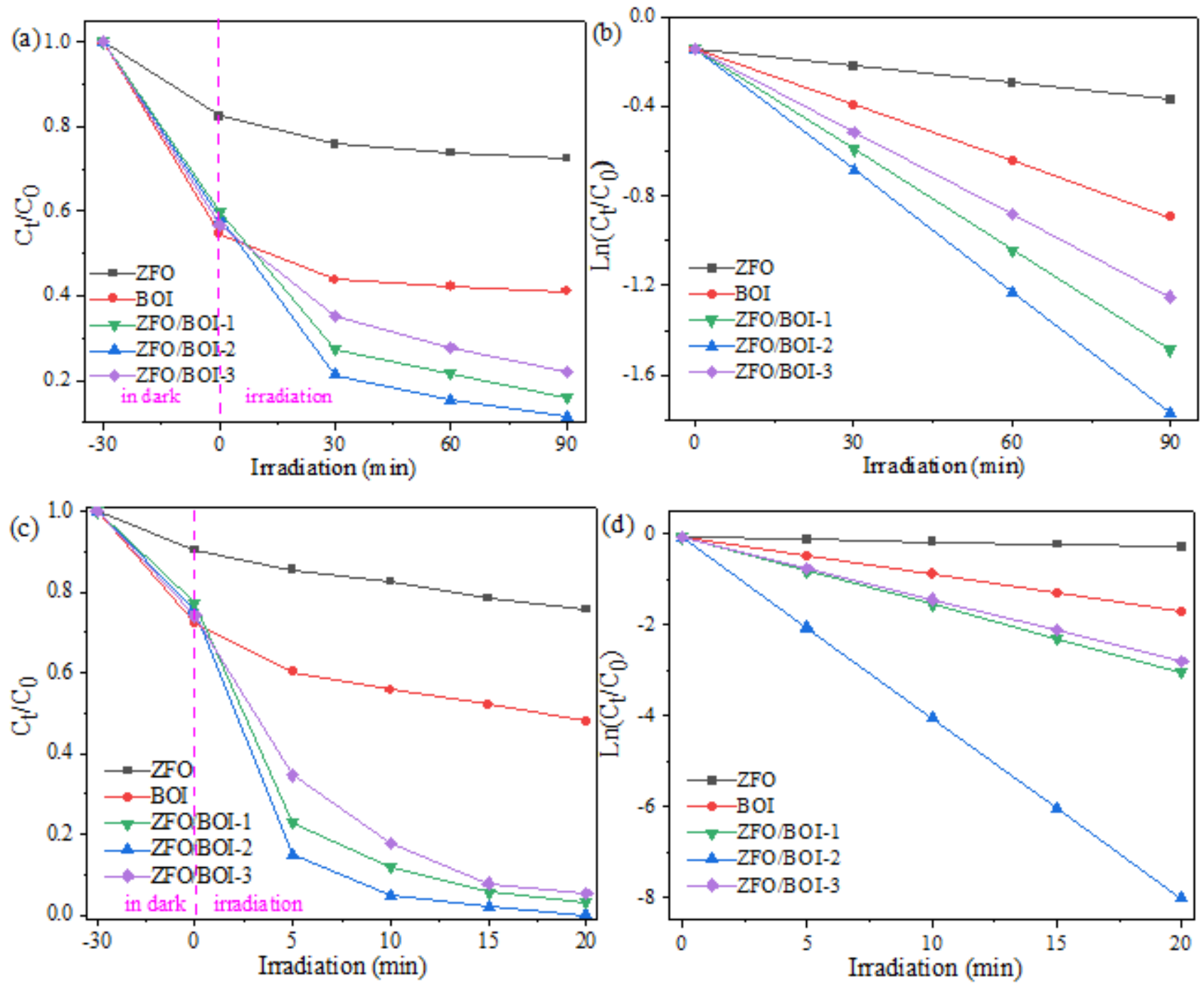

Figure 11

(a) The photocatalytic and (c) the Photo-Fenton degradation of RhB over time and (b) The photocatalytic and (d) the Photo-Fenton plots of $\ln (\mathrm{Ct} / \mathrm{CO})$ vs. irradiation time for pure ZFO, BOI and ZFO/BOI samples

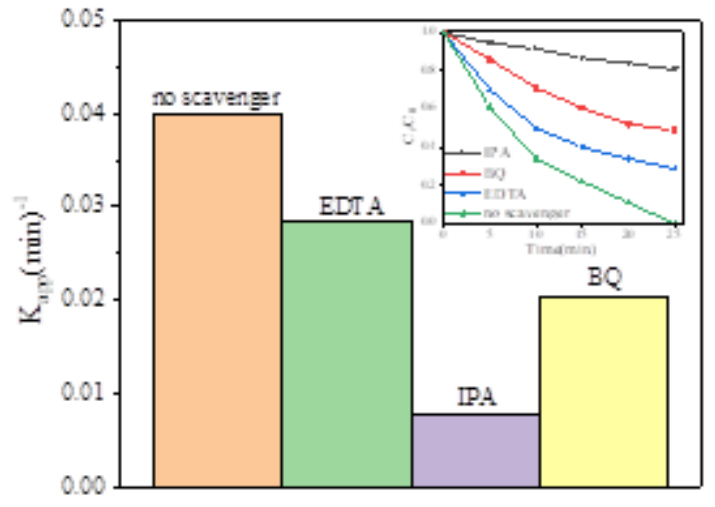

Figure 12

Photocatalytic degradation of ZFO/BOI -2 samples with different trapping agents 


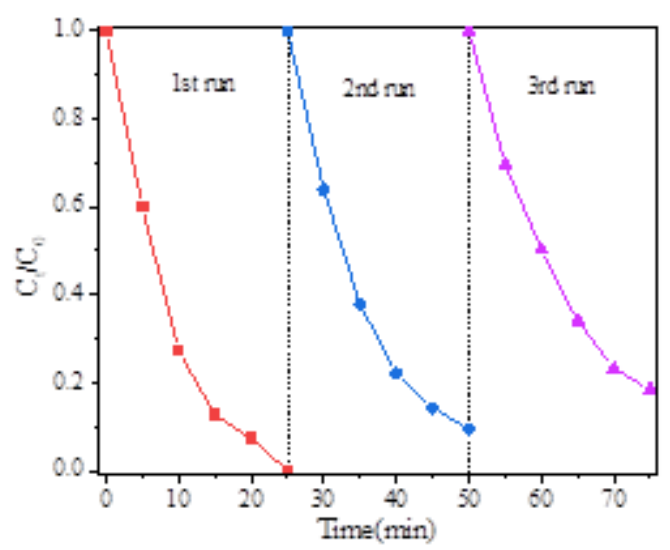

Figure 13

Recyclability of ZFO/BOI -2 for photocatalytic degradation of RhB

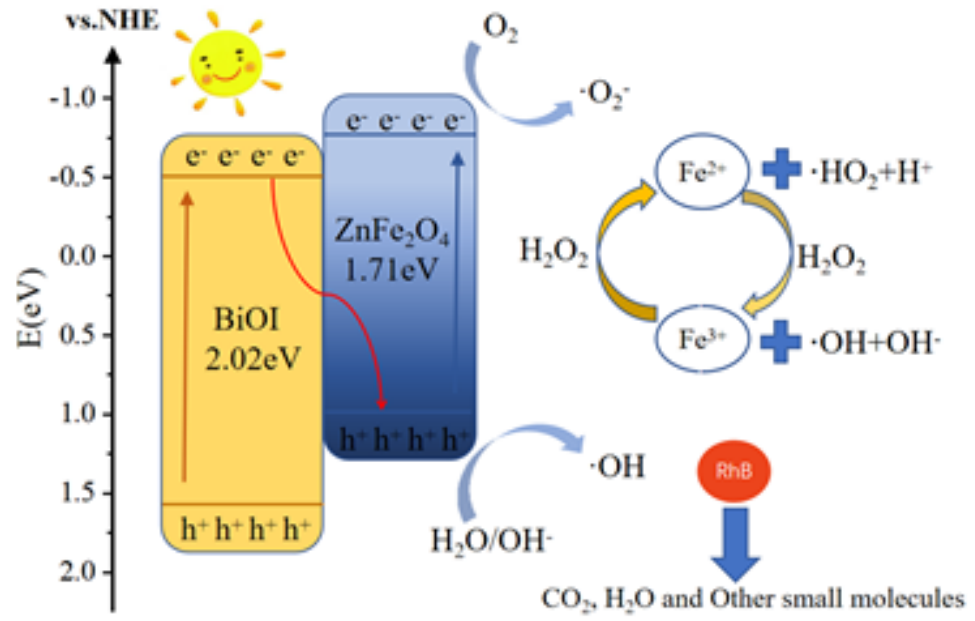

Figure 14

The schematic diagram of photocatalytic mechanism of the ZFO/BOI composites under simulated sunlight 